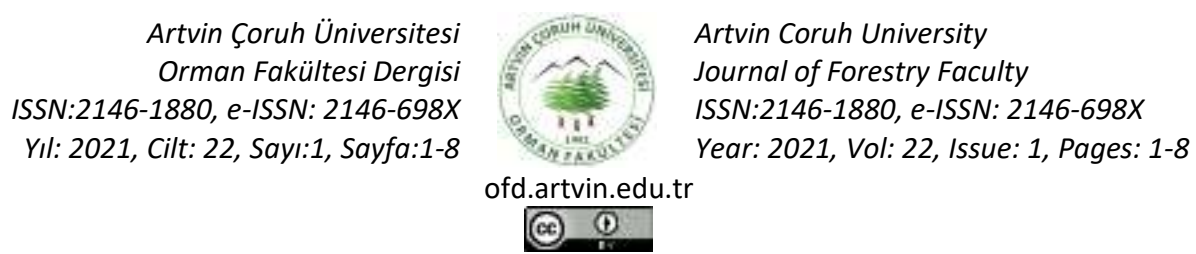

\title{
Sahilçamı (Pinus pinaster Ait.) plantasyon alanlarında el vincinin odun üretim çalışmalarında kullanımı
}

\section{The use of portable winch for forest harvesting operations in Pinus pinaster plantation areas}

\author{
Tolga ÖZTÜRK ${ }^{1}$, Necmettin ŞENTÜRK ${ }^{1}$ \\ 1 İstanbul Üniversitesi-Cerrahpaşa, Orman Fakültesi, Orman Mühendisliği Bölümü, 34473, Bahçeköy/istanbul
}

\section{Eser Bilgisi / Article Info}

Araştırma makalesi / Research article

DOI: 10.17474/artvinofd.774815

Sorumlu yazar / Corresponding author

Tolga ÖZTÜRK

e-mail: tozturk@istanbul.edu.tr

Geliş tarihi / Received

28.07.2020

Düzeltme tarihi / Received in revised form

19.10.2020

Kabul Tarihi / Accepted

12.11.2020

Elektronik erişim / Online available

12.05.2021

\section{Anahtar kelimeler:}

El Vinci

Sürütme

Odun Üretimi

Verim Analizi

Yakıt Tüketimi

\section{Keywords:}

Portable Winch

Skidding

Wood Harvesting

Productivity Analysis

Fuel Consumption

\begin{abstract}
Özet
Ülke nüfusunun artışına paralel olarak odun üretim miktarlarında da son yıllarda önemli artışlar görülmektedir. Odun üretim miktarlarında ortaya çıkan bu artış üretim çalışmalarında da yeniliklere gitmeyi zorunlu kılmaktadır. Özellikle odun üretim çalışmalarında taşınabilir ve düşük maliyetli yeni teknolojilerin ve makinelerin kullanımı önemli bir hal almıştır. Bu makineler arasında el vinçleri son yıllarda ülkemizde ve dünya ormancılık çalışmalarında da kullanılmaya başlanmıştır. Bu vinçler kurulumu ve sökülmesi yanında kullanım açısından da çok kullanışlı makinelerdir. Bu çalışmada, İstanbul Orman Bölge Müdürlüğü'ne bağlı Sarıyer Orman İşletme Şefliği sınırları içerisinde yer alan Sahilçamı plantasyon sahalarında el vincinin kullanımı incelenmiştir. Çalışmalar sonucunda el vincinin ortalama 50 metrelik sürütme mesafesinde saatlik verimi $1.10 \mathrm{~m}^{3} / \mathrm{sa}$ ve günlük verimi $8.80 \mathrm{~m}^{3} /$ gün olarak bulunmuştur. El vincinin saatlik yakıt tüketimi ise $1.4 \mathrm{lt} / \mathrm{sa}$ olarak belirlenmiştir.
\end{abstract}

\begin{abstract}
In parallel with the increase in the population in Turkey, there has been a significant increase in the amount of wood production in recent years. This increase, which occurs in the amount of wood production, makes it imperative to innovate in production of forest products. Especially in wood production, the use of portable and low-cost new technologies and machines has become important. Among these machines, portable winches have been used in forest operations in the world and in Turkey as well in recent years. These winches are very useful machines in terms of installation and uninstallation. In this study, the use of portable winch in the Sahilçamı plantation areas within the boundaries of Sarıyer Forest Operation Directorate affiliated to the Istanbul Forest Regional Directorate has been examined. As a result of the studies, the hourly yield of the portable winch at an average skid distance of 50 meters was found as $1.110 \mathrm{~m}^{3} / \mathrm{hr}$ and the daily yield was found as 8.800 $\mathrm{m}^{3} /$ day. Hourly fuel consumption of the hand winch was determined as $1.4 \mathrm{lt} / \mathrm{h}$.
\end{abstract}

\section{Giriş}

Insanların ormanları kullanması ve odun üretim çalışmaları asırlardır devam eden çalışmalardır. Odun üretiminde yarı ve tam mekanizasyonun gelişmesi özellikle II. Dünya savaşından sonra hız kazanmıştır (Moskalik ve ark. 2017). Ormancılıktaki odun üretim çalışmalarında kullanılan makineler kullanım amaçlarına, üreticilerine ve teknik özelliklerine göre değişiklik gösterse de dünya genelinde orman alanına sahip bütün ülkelerde kullanılmaktadır (Mellgren ve Claire 1989). Mekanik odun üretim yöntemlerinin yeterli düzeyde kullanılmaması durumunda bölmeden çıkarma maliyetlerinde artış görülmekte ve aynı zamanda ekosistem üzerinde önemli zararlara neden olabilmektedir (Akay ve ark. 2014). Üretim makinelerinin ormancılık çalışmalarında yoğun olarak kullanılması üretimin hız kazanmasına ve açık işletme olarak çalışan ormancılık sektörüne verimlilik kazandırmıştır. Bunun yanında, makinelerin yoğun kullanımı çevresel zararları da beraberinde getirmiştir. Bundan dolayı, odun üretim çalışmalarında teknolojik gelişmelere ve yeni makinelere yer vermekle birlikte ormana zarar verebilecek çevresel zararları da minimumda tutmamız gerekmektedir. Dere havzalarında, üretim alanlarında ve ormanlık alanlarda makineleşmenin getirmiş olduğu zararlar iyi analiz edilmeli ve yönetimler bu konuda önlemler almalıdır (LeDoux ve Huyler 2000). 
Odun üretim çalışmalarında ülkemizde farklı makineler kullanılmaktadır. Bunlar; motorlu testere, tarım traktörleri, sürütücüler, hava hatları, harvester şeklinde sıralanabilir. Bunun yanında, son yıllarda oluk sistemleri gibi farklı bölmeden çıkarma tesisleri de odun üretim çalışmalarında kullanılmaktadır (Acar ve ark. 2015). Tüm bu bölmeden çıkarma araçları yanında, dünya ormancılığından da son zamanlarda kullanılan el vinçleri uygun arazi şartlarında ve uygun ekipmanlar ile kullanılmaya başlanmıştır (Russell ve Mortimer 2005). El vinçleri odun hammaddesini sürütme konisi yardımıyla orman toprağı üzerinde sürüterek bölmeden çıkarma yeteneğine sahiptir (Aktekin 2018). Insan, hayvan gücünün ve traktörlerin kullanımı açısından uygun olmayan alanlarda taşınabilir el vinçleri ile odun hammaddelerinin kablo çekim ile bölmeden çıkarılması etkin bir alternatif olarak karşımıza çıkmaktadır (Gülci ve ark. 2014, Bilici ve ark. 2019). El vinçlerinin orman alanı içerisinde kullanımı açısından en önemli etken sürütme konilerinin kullanımıdır. Sürütme konisinin kullanımı toprak üzerinde sürütülen ürünün çevredeki yer örtücü, taş-kaya, kütük gibi engellere takılmasının önlemesi yanında, orman toprağında ve meşçere içerisinde dikili halde kalan ağaçlar ve fidanlar üzerinde meydana gelebilecek çevresel zararları da minimuma indirmektedir.

Bu çalışma İstanbul Orman Bölge Müdürlüğü’ne bağı Sarıyer Orman İşletme Şefliği sınırları içerisinde yer alan sahilçamı (Pinus pinaster Ait.) plantasyon sahalarında gerçekleştirilmiştir. Çalışmada amaçlanan, odun üretim çalışmalarında yeni teknolojilerin kullanılabilirliği ve ülkemiz ormanlık alanlarında bu makinelerin verimli olup olmadığının belirlenmesidir. Çalışma kapsamında, bölme içerisinde üretilen kısa boy tomruk ve sanayi odunun el vinci ile sürütülerek bölmeden çıkarılması incelenmiştir. El vincinin verimliliği, yakıt tüketimi ve bölmeden çıkarma çalışmalarında kullanılabilirliği gibi alternatifler araştırılmış, çeşitli sonuçlar ve öneriler ortaya çıkarılmıştır.

\section{MATERYAL ve YÖNTEM}

\section{Araştırma alanı}

Çalışma alanı olarak İstanbul Orman Bölge Müdürlüğü'ne bağlı Sarıyer Orman İşletme Şefliği sınırları içerisindeki 8 numaralı bölmede yer alan sahilçamı (Pinus pinaster Ait.) plantasyon alanları seçilmiş̧ir (Şekil 1). Sarıyer Orman İşletme Şefliği $41^{\circ} 08^{\prime} 13^{\prime \prime}-41^{\circ} 15^{\prime} 54^{\prime \prime}$ kuzey enlemleriyle, $28^{\circ} 56^{\prime} 01^{\prime \prime}$ - 29 $29^{\circ} 06^{\prime} 59^{\prime \prime}$ doğu boylamları arasında bulunmaktadır. Arazinin en yüksek yeri $234 \mathrm{~m}$. ile Kayranbaşı ve Arapöldüren tepeleridir. En alçak noktası ise deniz seviyesidir (Anonim 2012). Alan plantasyon sahası olup, arazinin eğimi \%5-25 arasında değişiklik göstermektedir. Bölme içerisinde yoğun bir yer örtücü ve sarıııı bitki grupları bulunmaktadır. Alan içerisinde tarım traktörünün çalışabilmesi için belirli mesafelerde sürütme yol ve şeritleri açılmıştır. Bölme içerisine giren tarım traktörleri ürünleri sürütme ve taşıma şeklinde bölmeden çıkarmaktadır. Bölmenin toprak tipi kahverengi orman toprağıdır. Meşçere ortalama boyu $16 \mathrm{~m}$, ortalama göğüs yüksekliği çapı $(1.30 \mathrm{~m}) 28 \mathrm{~cm}$ olarak belirlenmiştir. Bölme içerisinde üretilen odun hammaddesi tipleri 3 m'lik kısa boy tomruk ve $1.25 \mathrm{~m}$ boyunda sanayi odunu şeklindedir. Aynı zamanda, yakacak odun üretimi de gerçekleşmiştir.

\section{El Vincinin Arazide Uygulanması}

Üretim çalışmasında kullanılan Honda marka PCW3000 model el vincinin teknik özellikleri Çizelge $1^{\prime}$ de verilmiştir. El vincinin sürütme kablosunun uzunluğu $100 \mathrm{~m}$ olup, kablo $10 \mathrm{~mm}$ kalınlığında sentetik kablodur. El vinci motoru ve kablosu yanında üretim alanı içerisinde sürütme konisi, zincir çoker (1.5 m), metal kancalar, metal kilitler ve makara kullanılmıştır. Zincir çoker sentetik halat ucuna bağlandıktan sonra sürütülecek olan ürüne çoker yardımıyla sarılarak bağlanmaktadır (Şekil 2). El vinci bölme içerisindeki kalın çaplı bir ağaca 2 adet metal kanca ve bir kuşak yardımıyla monte edilerek kullanılmaktadır. El vincinin alana taşınması, monte edilmesi ve demontajı çok kısa zaman almaktadır. 

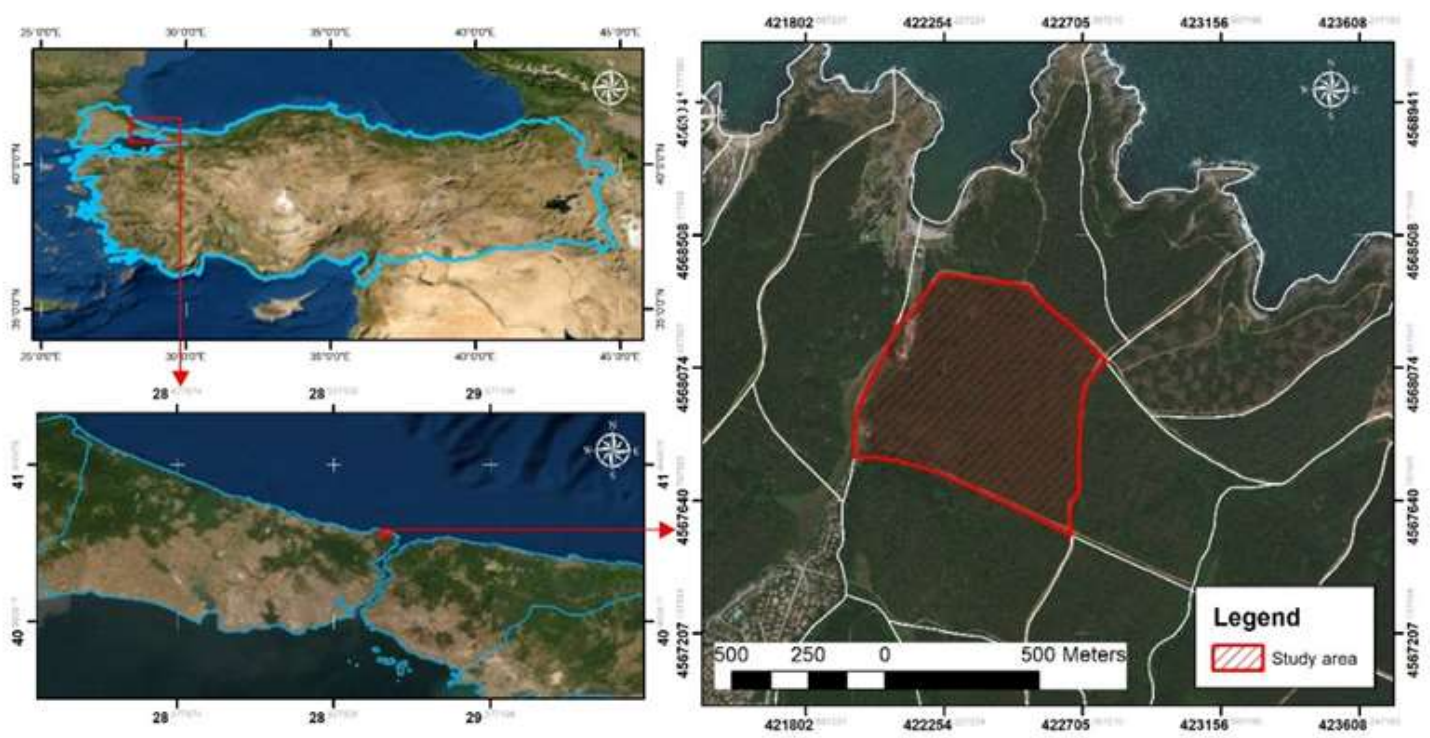

Şekil 1. Çalışma alanının konumsal haritası

Çizelge 1: PCW3000 Honda el vincinin teknik özellikleri

\begin{tabular}{lc}
\hline Özellikler & El vinci \\
\hline Yüklü maksimum çekme kuvveti (kg) & 700 \\
Ağırlık (kg) & 9.5 \\
Uzunluk / Genişlik / Yükseklik (cm) & 28.9 / 35 / 26.1 \\
Polyster askı (mm x m) & $60 \times 2$ (PCA-1260) \\
Hız (m/dak) & 10 \\
Tambur genişliği (mm) & 76 \\
Halat çapları (mm) & 10 - 16 \\
Motor (cc) & Tam zamanlı GX-35 \\
Yağ deposu (santilitre) & 10 \\
Yağ tipi & SAE 10W-30API SJ \\
Benzin deposu (lt) & 1 \\
\hline
\end{tabular}

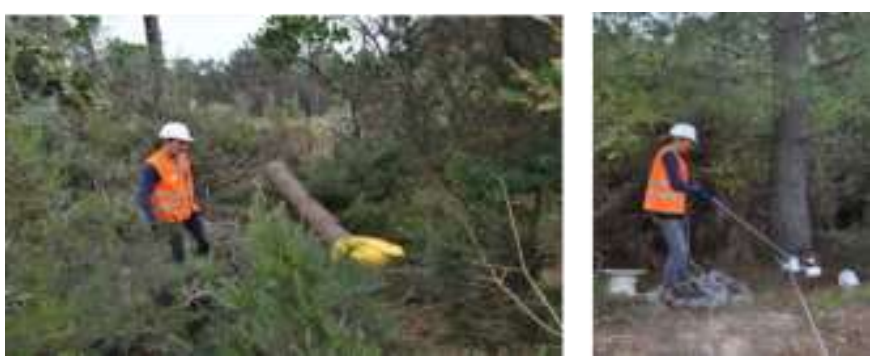

Şekil 2. Bölme içerisinde el vincinin kullanımı

\section{Verim Analizi}

Bu çalışmada Honda marka PCW3000 model el vincinin sanayi odununun bölmeden çıkarma çalışmaları sırasındaki verimliliği incelenmiştir. El vincinin verimliliğinin bulunması için sürütme çalışmaları sırasında zaman etütleri yapıımıştır. Zaman değerlerinin belirlenmesi çalışmaları, "belirli koşullarda yapılan işlerin elemanlarını, süresini ve zaman değerlerini kayıt eden ve bu şekilde araziden toplanan bilgileri analiz ederek, çalışmanın açıklanan performansta yapılabilmesi için gerekli olan süreyi belirlemekte tercih edilen bir iş ölçme tekniğidir" şeklinde açıklanır (Gümüşay 2006). Odun üretim çalışmalarında her bir aşama zaman döngüsü şeklinde belirlenerek farklı üretim araçlarının verimliliğinde zaman etütleri kullanılmaktadır (Hiesl ve Benjamin 2012, Mcdonald ve Fulton 2005). Bu zaman etütlerinde tekrarlı zaman ölçme tekniği uygulanmıştır. Zaman etütleri yapılırken el vincinin bölme içerisindeki sürütme çalışmaları 5 ayrı aşamaya ayrılarak incelenmiştir. Bu aşamalar aşağıda sırasıyla verilmiştir:

1. Kablonun ve sürütme konisinin bölme içerisine çekilme süresi (ÇS): El vincinin kablosunun ve sürütme konisinin bir çalışan yardımıyla bölme içerisindeki en yakın ürüne götürülme süresidir (dak).

2. Yükün bağlanma süresi (YBS): Çalışanın sürütme konisi içerisindeki kabloya ürünü bağlama süresidir (dak).

3. Kablonun sürütme konisi ve yük ile birlikte bölme dışına çekilme süresi (SS): Üretim alanı içerisinde koniye ve halata bağlanan ürünün en yakın orman yolu kenarına sürütme süresidir (dak). 
4. Yükün çözülme süresi (YÇS): Orman yolu kenarına sürütülen yükün halattan ve koniden çözülme süresidir (dak).

5. Zaman kaybı (ZK): Tüm sürütme çalışması esnasında meydana gelen zaman kayıplarının süresidir (dak).

Bu beş aşamanın son kısmında toplam zaman ile her bir seferin süresi tayin edilmiştir. Zaman etütleri sırasında her bir safhada el vinci tarafından sürütülen ürünün sürütme mesafesi (SM), sürütülen ürün adedi (UA) ve sürütülen ürün hacim $(H)$ bilgileri de her bir aşamada ayrı ayrı olarak kaydedilmiştir.

\section{BULGULAR}

Bu çalışma İstanbul Orman Bölge Müdürlügü’ne bağlı Sarıyer Orman İşletme Şefliği sınırları içerisinde yer alan 8 numaralı Sahilçamı plantasyon sahasında gerçekleştirilmiştir. Çalışma 2019 yılının Haziran ayında yapılmıştır. Bölme içerisinde ağaçlar motorlu testere ile kesildikten sonra alan içerisinde boylanmış, traktörler ve el vinci yardımıyla bölmeden çıkarılmıştır. Bölme içerisinde üretilen ürünler $3 \mathrm{~m}$ kısa boy tomruk ve $1.25 \mathrm{~m}$ uzunluğunda boylanmış sanayi odunu şeklindedir.
Ürünler alandan çıkarıldıktan sonra orman yolu kenarında soyma aparatı ile soyulduktan sonra istif edilmişlerdir.

El vinci orman yolu kenarındaki kalın çaplı bir ağaca monte edildikten sonra bölmeden çıkarma çalışmaları gerçekleştirilmiştir. Bölmeden çıkarma çalışmalarında sürütme mesafesi 20 ile 75 metre mesafelerde değişiklikler göstermiştir. Ortalama sürütme mesafesi 50 $\mathrm{m}$ olarak hesap edilmiştir. Arazi çalışmalarında el vincini kullanan bir çalışan, bölme içerisinde ürünlerin çekme kablosuna bağlayan bir çalışan olmak üzere toplam iki kişilik bir ekip çalışmıştır. El vinci $36 \mathrm{~cm}$ çapında bir Sahilçamı ağacına monte edilmiş ve tüm zaman etütlerinde sürütme konisi kullanılmıştır. Alandaki yoğun diri örtüden dolayı sürütme konisi olmadan çalışmalar gerçekleştirilememiştir. Sürütme konisi olmadan denemeler yapılmış sürütülen ürünler neredeyse her seferinde diri örtüye takılmış ve bu durumda da el vincinin zorlanmasına neden olmuştur. İ̧̧ güvenliği açısından ve herhangi bir kaza riskine karşın koni olmadan çalışma yapılmamıştır. Bölmeden çıkarmada çalışanlar reflektörlü yelek, baret ve eldiven kullanmışlardır. El vinci ile çalışmada koruyucu ekipmanların kullanımı önemli bir etkendir. El vinci ile yapılan sürütme çalışmalarında toplam 20 zaman etüdü yapılmış ve ortalama süreler bulunmuştur (Çizelge 2).

Çizelge 2. PCW3000 El vincinin bölmeden çıkarma zaman değerleri

\begin{tabular}{|c|c|c|c|c|c|c|c|c|c|c|c|c|}
\hline Sira No & Ürün Tipi & $\begin{array}{l}\text { Sürütme Mesafesi } \\
(\mathrm{m})\end{array}$ & $\begin{array}{l}\text { Ürün Boyu } \\
\text { (m) }\end{array}$ & $\begin{array}{l}\text { Ürün Sayısı } \\
\text { (Adet) }\end{array}$ & $\begin{array}{l}\text { Orta Çap } \\
\text { (cm) }\end{array}$ & $\begin{array}{l}\text { Hacim } \\
\left(\mathrm{m}^{3}\right)\end{array}$ & $\begin{array}{c}\text { ÇS } \\
\text { (dak) }\end{array}$ & $\begin{array}{l}\text { YBS } \\
\text { (dak) }\end{array}$ & $\begin{array}{c}\text { SS } \\
\text { (dak) }\end{array}$ & $\begin{array}{l}\text { YÇS } \\
\text { (dak) }\end{array}$ & $\begin{array}{l}\text { ZK } \\
\text { (dak) }\end{array}$ & $\begin{array}{c}\text { Toplam Zaman } \\
\text { (dak) }\end{array}$ \\
\hline 1 & Sanayi Od. & 53 & 1.25 & 2 & $21 / 24$ & 0.23 & 0.46 & 2.03 & 3.52 & 0.27 & 0.15 & 7.23 \\
\hline 2 & Tomruk & 55 & 3 & 1 & 30 & 0.212 & 1.08 & 1.18 & 5.24 & 0.24 & & 8.14 \\
\hline 3 & Sanayi Od. & 52 & 1.25 & 3 & $17 / 20 / 24$ & 0.232 & 0.5 & 1.53 & 4.3 & 0.21 & & 7.34 \\
\hline 4 & Tomruk & 40 & 3 & 1 & 22 & 0.114 & 0.58 & 0.25 & 3.23 & 0.14 & & 5 \\
\hline 5 & Tomruk & 20 & 3 & 1 & 26 & 0.159 & 0.32 & 2.28 & 2.13 & 0.2 & 0.14 & 5.47 \\
\hline 6 & Tomruk & 35 & 3 & 1 & 20 & 0.094 & 0.45 & 0.13 & 2.01 & 0.22 & & 3.21 \\
\hline 7 & Sanayi Od. & 50 & 1.25 & 2 & $25 / 30$ & 0.12 & 1.15 & 0.34 & 3.31 & 0.3 & 0.1 & 6 \\
\hline 8 & Sanayi Od. & 48 & 1.25 & 2 & $25 / 27$ & 0.106 & 0.52 & 1.47 & 3.3 & 0.18 & & 6.27 \\
\hline 9 & Tomruk & 60 & 3 & 1 & 24 & 0.136 & 1.27 & 0.38 & 5.34 & 0.1 & & 7.49 \\
\hline 10 & Tomruk & 65 & 3 & 1 & 30 & 0.212 & 1.29 & 1.38 & 6.52 & 0.18 & & 10.17 \\
\hline 11 & Sanayi Od. & 45 & 1.25 & 2 & $20 / 33$ & 0.116 & 0.54 & 2.1 & 3.29 & 0.15 & & 6.48 \\
\hline 12 & Tomruk & 68 & 3 & 1 & 23 & 0.125 & 1.2 & 0.22 & 5.52 & 0.13 & 0.2 & 8.07 \\
\hline 13 & Sanayi Od. & 55 & 1.25 & 3 & $14 / 21 / 23$ & 0.101 & 1.06 & 2.35 & 6.52 & 0.25 & 1.1 & 12.08 \\
\hline 14 & Tomruk & 75 & 3 & 1 & 25 & 0.147 & 1.43 & 0.55 & 7.5 & 0.18 & & 10.46 \\
\hline 15 & Sanayi Od. & 72 & 1.25 & 1 & 42 & 0.138 & 1.35 & 1.4 & 5.47 & 0.25 & 1.08 & 10.35 \\
\hline 16 & Tomruk & 42 & 3 & 1 & 22 & 0.114 & 1.31 & 0.33 & 4.34 & 0.3 & & 7.08 \\
\hline 17 & Sanayi Od. & 46 & 1.25 & 2 & 19 / 19 & 0.045 & 0.57 & 2.3 & 3.18 & 0.38 & & 7.23 \\
\hline 18 & Sanayi Od. & 52 & 1.25 & 3 & $15 / 15 / 16$ & 0.045 & 1.05 & 0.35 & 3.1 & 0.28 & & 5.18 \\
\hline 19 & Sanayi Od. & 25 & 1.25 & 1 & 45 & 0.159 & 0.35 & 0.25 & 2.28 & 0.34 & & 4.02 \\
\hline 20 & Sanayi Od. & 30 & 1.25 & 5 & $8 / 10 / 14 / 15 / 16$ & 0.063 & 0.45 & 1.35 & 2.16 & 0.28 & & 5.04 \\
\hline Ort. & & 50 & & 1.75 & & 0.133 & 1.04 & 1.19 & 4.2 & 0.23 & 0.1 & 7.16 \\
\hline Top. & & & & 35 & & 2.668 & 21.33 & 26.17 & 86.36 & 7.37 & 3.17 & 146.51 \\
\hline
\end{tabular}


El vinci ile yapılan zaman etütlerinin sonucu incelendiğinde; sürütme mesafesi ve toplam zaman arasındaki ilişki doğrusal artan bir ilişkidir. Sürütme mesafesi arttıkça toplam zamanda artmaktadır (Şekil 3). Toplam zaman içerisindeki zaman etüdü aşamalarının dağılımı Şekil 4'de her bir zaman aşamasının yüzdelik dilimlerinin durumu Şekil 5'de gösterilmiştir. Zaman etütlerinde en fazla süreyi $\% 62$ ile sürütme zamanı almaktadır. En az süreyi ise \%2 ile zaman kaybı aşaması oluşturmaktadır.

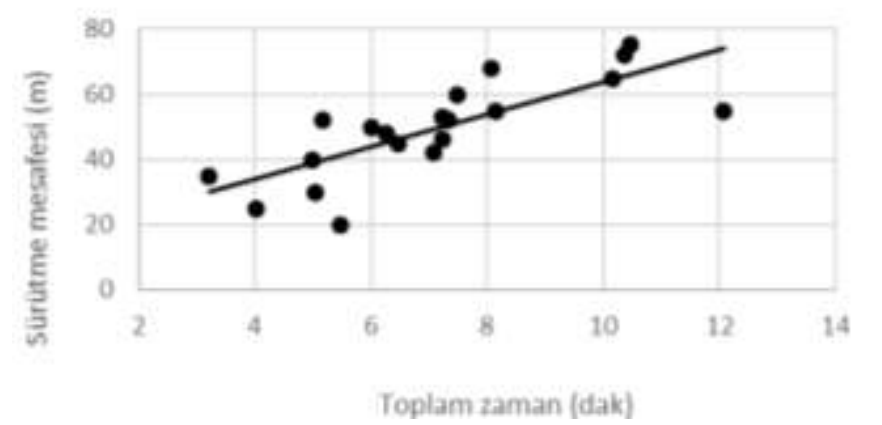

Şekil 3. Sürütme mesafesi ve toplam zaman arasındaki ilişki

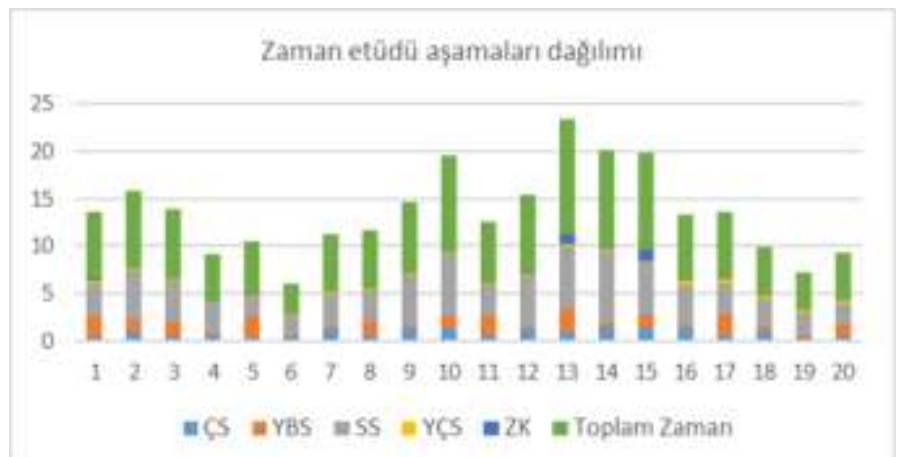

Şekil 4. Zaman etüdü aşamalarının toplam zaman içerisindeki zamansal dağıııı

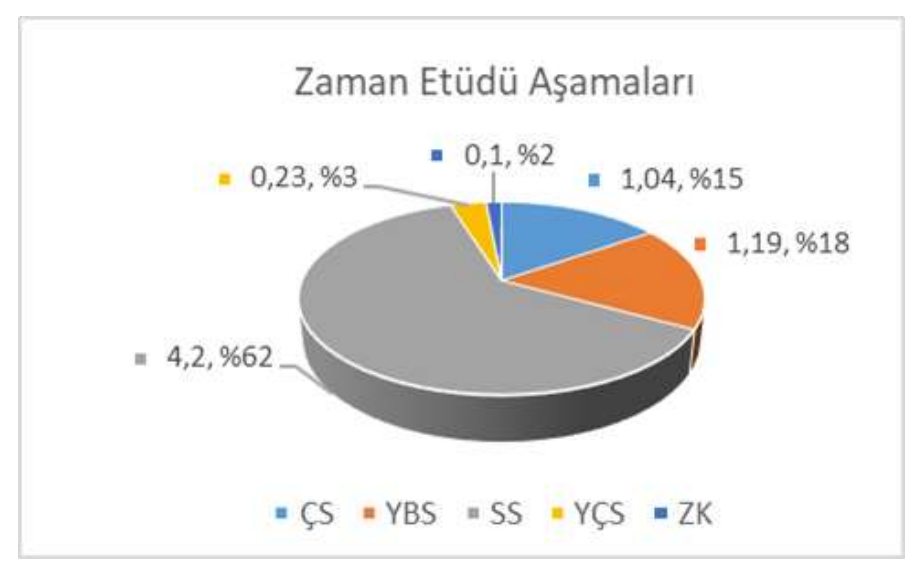

Şekil 5. Zaman etüdü aşamalarının yüzdesel dağılımı
Çizelge 2 incelendiğinde, bu çalışmada toplam 20 adet zaman etüdü yapılmıştır. Ortalama $50 \mathrm{~m}$ 'lik sürütme mesafesinde bir zaman etüdü aşaması ortalama 7.16 dakika sürmüştür. Bu süre içerisinde en fazla zamanı ortalama 4.20 dakika ile ürünün sürütme zamanı almıştır. En az süreyi ise ortalama 0.10 dakika ile zaman kaybı aşaması oluşturmuştur. El vincinin bir seferde bölmeden çıkardığı ürün miktarı ise $0.133 \mathrm{~m}^{3}$ olarak bulunmuştur. El vincinin saatlik verimi $1.10 \mathrm{~m}^{3}$ ve günlük verimi ise 8.80 $\mathrm{m}^{3}$ olarak belirlenmiştir. El vincinin bir depo yakıtı sürütme mesafelerine bağlı olmakla beraber ortalama 57 sefer bölmeden çıkarma yapabilmektedir.

El vincinin çalışması esnasında zaman etütlerinde ortaya çıkan zaman kayıpları iki şekilde oluşmaktadır. Bunlar; ürünün kablo bağlantısının açılması ve ürünün diri örtüye takılması şeklindedir. Toplam 20 adet zaman etüdü içerisinde 6 kez zaman kaybı yaşanmıştır. Bunlardan 4 tanesi yükün sürütme işlemi sırasında çözülmesi, iki tanesi ise sürütme konisinin yoğun diri örtüye takılması şeklinde gerçekleşmiş̧ir.

Bu çalışmada zaman değerlerinin incelenmesi için SPSS 21.0 istatistik programının regresyon analiz modeli kullanılmıştır (Anonim 2019). Bölmeden çıkarma çalışmalarında belirlenen her bir seferin zaman değerleri ve diğer değerlerin ortalamaları Çizelge 3'de verilmiştir.

Regresyon analizleri Enter yöntemi ile yapılmıştır. Regresyon analizinde bağımlı değişken olarak Toplam Zaman (TZ), bağımsız değişkenler olarak Sürütme Mesafesi (SM), Ürün sayısı (US) ve Hacim (H) alınmıştır. El vinci ile yapılan toplam 20 adet zaman ölçümü lineer regresyon analizi çalışılmıştır. Bu regresyon modeli aşağıdaki gibi belirlenmiştir;

$\mathrm{TZ}=0.009+0.118 \times \mathrm{SM}+0.247 \times \mathrm{US}+6.163 \times \mathrm{H}$

Burada;

TZ = Toplam Sürütme Zamanı (dak/sefer)

SM = Sürütme Mesafesi (m)

US = Ürün Sayısı (adet)

$\mathrm{H}=\operatorname{Hacim}\left(\mathrm{m}^{3}\right)^{\prime}$ dür. 
Çizelge 3. El vinci için zaman değerlerinin özeti

\begin{tabular}{|c|c|c|c|c|}
\hline Faktörler & Ort. & Std. Sapma & Min. & Maks. \\
\hline Kablonun ve koninin bölme içerisine çekilme süresi (dak) & 1.04 & 0.396 & 0.32 & 1.43 \\
\hline Yükün bağlanma süresi (dak) & 1.19 & 0.832 & 0.13 & 2.35 \\
\hline Kablonun yükle birlikte bölme dışına çekilme süresi (dak) & 4.20 & 1.603 & 2.01 & 7.50 \\
\hline Yükün çözülme süresi (dak) & 0.23 & 0.074 & 0.10 & 0.38 \\
\hline Zaman kaybı (dak) & 0.10 & 0.488 & 0.10 & 1.10 \\
\hline Toplam zaman (dak) & 7.16 & 2.306 & 3.21 & 12.08 \\
\hline Sürütme mesafesi $(\mathrm{m})$ & 49.40 & 14.493 & 20.00 & 75.00 \\
\hline Yük hacmi $\left(m^{3}\right)$ & 0.133 & 0.054 & 0.045 & 0.232 \\
\hline Ürün sayısı (adet) & 1.75 & 0.768 & 1.00 & 5.00 \\
\hline
\end{tabular}

Bu regresyon analizinde önem seviyesi 0.05 olarak alınmış ve $\mathrm{R}^{2}=\% 62.3$ olarak bulunmuştur. Bunun anlamı, model toplam varyansın \%62.3'ünü açıklıyor demektir. Bu analizde, toplam zaman bağımlı değişkeni ile Sürütme Mesafesi, Ürün Sayısı ve Hacim arasındaki ilişki incelenmiştir. Çoklu korelasyon katsayısı (R) toplam değişkenlerin \%79'unu oluşturmaktadır. $F$ değeri istastiki açıdan (8.832) anlamlı çıkmıştır. Varyans Enflasyon Faktörü (VIF) 10'nun altında, tolerans istatistikleri de 0.2'nin üstünde olduğundan modelde herhangi bir problem yoktur ve tahmin değişkenleri arasında mükemmel doğrusal bir ilişkiden söz edilemez (Çizelge 4). Otokorelasyon belirleme yöntemlerinden biri olan Durbin-Watson testi sonucu 2.155 olarak çıkmıştır. Durbin Watson değeri 2'ye çok yakın olmakla birlikte değer 2'nin üstünde çıktığı için modelde negatif otokorelasyon olduğu görülmüştür (Çizelge 4). Regresyon analizinin histogram eğrisi Şekil 6 ' da verilmiştir.

Çizelge 4. Regresyon analizi model özeti

\begin{tabular}{|c|c|c|c|c|c|c|c|c|c|c|}
\hline \multirow{2}{*}{$\begin{array}{l}\overline{0} \\
\frac{0}{0} \\
\Sigma\end{array}$} & \multirow{2}{*}{$\mathbf{R}$} & \multirow{2}{*}{$\mathbf{R}^{2}$} & \multirow{2}{*}{$\begin{array}{l}\text { Düzeltilmiş } \\
\mathbf{R}^{2}\end{array}$} & \multirow{2}{*}{ Standart tahmin hatası } & \multicolumn{5}{|c|}{ İstatiksel değişenler } & \multirow{2}{*}{$\begin{array}{l}\text { Durbin } \\
\text { Watson }\end{array}$} \\
\hline & & & & & $\begin{array}{c}R^{2} \\
\text { değişimi }\end{array}$ & $\mathbf{F}$ & df1 & df2 & $\begin{array}{c}\text { F anlamlılık } \\
\text { düzeyi }\end{array}$ & \\
\hline 1 & $0.790^{\mathrm{a}}$ & 0.623 & 0.553 & 1.53584 & 0.623 & 8.832 & 3 & 16 & 0.001 & 2.155 \\
\hline
\end{tabular}

Çizelge 5. Anova testi

\begin{tabular}{lccccc}
\hline Model & Karelerin toplamı & df & Ort. Kare & F & Anlamlılık \\
\hline Regression & 62.497 & 3 & 20.832 & 8.832 & $0.001^{\text {b }}$ \\
1 Residual & 37.741 & 16 & 2.359 & & \\
Toplam & 100.238 & 19 & & & \\
\hline
\end{tabular}

a. Bağımlı değişken: $\mathrm{TZ}$

b. Tahmin: (Sabit), H, SM, US

Çizelge 6. Regresyon analizinde modelin istatistiksel karakteristikleri

\begin{tabular}{|c|c|c|c|c|c|c|c|c|c|c|}
\hline \multirow{2}{*}{$\begin{array}{l}\bar{d} \\
\frac{0}{0} \\
\Sigma\end{array}$} & & \multicolumn{2}{|c|}{ Standart olmayan katsayılar } & \multirow{2}{*}{$\begin{array}{c}\text { Standart katsayılar } \\
\text { Beta }\end{array}$} & \multirow{2}{*}{$\mathbf{t}$} & \multirow{2}{*}{ Anlamlılık } & \multicolumn{2}{|c|}{ Korelasyon } & \multicolumn{2}{|c|}{ Doğrusallık İstatistikleri } \\
\hline & & B & Standart Hata & & & & Kısmi & Bölüm & Tolerans & VIF \\
\hline \multirow[t]{4}{*}{1} & Sabite & 0.009 & 1.730 & & 0.005 & 0.996 & & & & \\
\hline & SM & 0.118 & 0.025 & 0.765 & 4.812 & 0.000 & 0.769 & 0.738 & 0.932 & 1.073 \\
\hline & US & 0.247 & 0.353 & 0.115 & 0.701 & 0.493 & 0.173 & 0.108 & 0.871 & 1.148 \\
\hline & $\mathrm{H}$ & 6.163 & 6.854 & 0.148 & 0.899 & 0.382 & 0.219 & 0.138 & 0.863 & 1.158 \\
\hline
\end{tabular}

a. Bağımlı değişken: TZ 


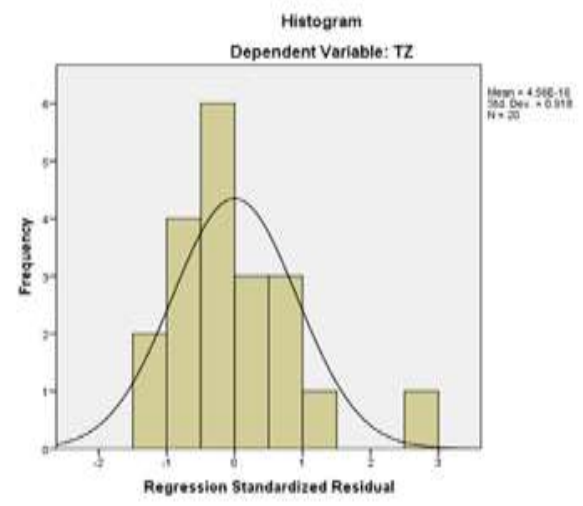

Şekil 6. Zaman tüketim modelinin histogramı

\section{TARTIŞMA}

$\mathrm{Bu}$ çalışmada, odun üretimi sırasında el vincinin verimliliğini bulabilmek için zaman etütleri yapılmıştır. Yapılan zaman etütleri sonucunda el vincinin saatlik verimi $1.10 \mathrm{~m}^{3}$, günlük verimi ise $8.80 \mathrm{~m}^{3}$ olarak bulunmuştur. Ortalama bir seferde çekilen yük miktarı $0.133 \mathrm{~m}^{3}$ tür. Gülci ve ark. (2017) tarafından yapılan çalışmada, kar üzerinde el vinci ile yapılan sürütme çalışmalarında $50 \mathrm{~m}$ sürütme mesafesinde ortalama \%25 arazi eğiminde ortalama verim değerleri $0.110-2.060 \mathrm{~m}^{3}$ aralığında bulunmuştur (Gülci ve ark. 2017). Diğer bir çalışmada; Akay ve ark. (2014) 60 m'lik ortalama sürütme mesafesinde el vincinin verimini $3.81 \mathrm{~m}^{3} / \mathrm{sa}$ olarak belirlemişlerdir. Bu iki çalışmada kullanılan el vinçleri PCW5000 (900 kg çekme gücü) modeldir. Bunun yanında, bu çalışmadaki bulunan verim değeri $\left(1.10 \mathrm{~m}^{3} / \mathrm{sa}\right)$ el vincinin modeli düşük (PCW3000 $700 \mathrm{~kg}$ çekme gücü) olmasına rağmen daha yüksek olarak kabul edilebilir. Farklı model el vinçleri de ormancılık çalışmalarında kullanılmaktadır. Bununla ilgili yapılan diğer bir çalışmada ise; ortalama 25 m sürütme mesafesinde toplam 13.23 dakikada $0.60 \mathrm{~m}^{3}$ ürün bölmeden çıkarılmıştır. Burada makinenin saatlik verimi $2.690 \mathrm{~m}^{3}$ tür (Sticha ve ark. 2018). Ülkemizde yapılan diğer bir çalışmada ise; oluk sistemi içerisinde PCW5000 model el vinci ile ortalama \%35 eğimde ve ortalama $55.8 \mathrm{~m}$ sürütme mesafesinde yapılan çalışmada verim $5.92 \mathrm{~m}^{3} / \mathrm{sa}$ olarak bulunmuştur (Acar ve ark. 2015). Bu çalışmadaki el vincinin verimi oluk sistemi ile birlikte kullanılan el vincinin veriminden daha düşük bulunmuştur. Oluk sistemi içerisinde taşınan ürünler herhangi bir engelle karşılaşmadıkları için verim daha yüksek bulunmuştur.
El vinci ile yapılan bu çalışmada verim düşük bulunmuştur. PCW3000 model el vinci ormancllık çalışmaları için kapasite olarak yeterli gelmemiştir. Bir üst model olan ve çekim ağırlığı 900 kg olan PCW5000 model el vinçleri ormancılık çalışmaları için daha uygundur. Çalışmada zaman kayıplarının toplam zamana etkisi çok fazla çıkmamıştır. Yapılan etütler içerisinde zaman kayıpları iki farklı şekilde ortaya çıkmıştır. Bunlar; ürünün kablo bağlantısının açılması ve ürünün diri örtüye takılması şeklindedir. Zaman kayıplarında ürünün çekim esnasında çözülmesi şeklindeki zaman kaybı daha fazla görülmüştür. Arazi yapısına ve bölme içerisindeki diri örtü yoğunluğuna göre zaman kayıplarının sayısı azalabilir. Aynı zamanda, el vinci ile çalışma kişilerin ürün bağlantılarını kontrollü bir şekilde yapması da zaman kayıplarını azaltıcı yönde olacaktır.

Odun hammaddesinin bölmeden çıkarılması, ormancılık çalışmaları içerisinde en fazla zaman alan ve iş güvenliği açısından en önemli çalışmalardan ilkidir. Odun hammaddesinin bölmeden çıkarılmasında farklı makine tipleri ve teknikler kullanılmaktadır. El vinçleri de son yıllarda ormancılık çalışmalarında kullanılan makinelerden biridir. Bu makineler yardımıyla ürünler direkt orman zemininde sürütüldüğü gibi sürütme konileri, oluk sistemleri gibi farklı transport araç-gereçleri ile de kullanılabilir (Acar ve ark. 2015, Gülci ve ark. 2014).

\section{ÖNERILER}

$\mathrm{Bu}$ çalışmanın ışığında el vincinin ormancılık çalışmalarında kullanımı açısından aşağıdaki öneriler getirilmiştir;

- Odun üretim çalışmalarında özellikle diri örtünün yoğun olarak bulunduğu alanlarda sürütme çalışmalarında mutlaka sürütme konisi kullanılmalıdır.

- El vinçlerinin çekim güçleri göz önünde bulundurularak sürütme için bağlanan ürünlerin ebatları ve ağırıkları ona göre seçilmelidir. Ağır olan yükler makinenin verimini düşürmekte ve iş kaza riskini arttırmaktadır.

- Yokuş yukarı çekimlerde el vinçleri oluk sistemleri içerisinde kullanıldığı takdirde verimleri daha yüksek olacaktır. 
- El vinçleri depo alanlarında veya orman içi açıklıklarda kamyonlara yapılan yükleme çalışmalarında da verimli bir şekilde kullanılabilir.

- El vinçleri ile çalışma esnasında koruyucu elbiselerin kullanımı çok önemlidir. İş sağlığı ve güvenliği açısından özellikle eldiven, gözlük, baret, reflektörlü yelek ve koruyucu ayakkabının kullanımı gereklidir.

- Bu çalışma esnasında yapılan gözlemler sonucunda el vinçlerinin kullanımı çevresel zararları minimuma indirebileceği gözlenmiştir. Sürütme işleminin yavaş seyretmesi, sürütme konisinin kullanılması ve çalışanın ürünle birlikte hareket etmesi özellikle meşçerede kalan ağaçlara ve orman toprağına verilen zararı minimumda tutabilecektir.

- El vinçlerinin hafif ve taşınabilir olması, kurulum ve sökülmesinin kolay olması ormancılık çalışmalarında avantaj sağlamaktadır.

- El vinçleri traktörlerin rahat bir şekilde bölme içerisine giremediği, yoğun gençlik olan alanlarda ve dere içlerindeki ürünlerin bölmeden çıkarılmasında yararlı olacak bir makinedir.

\section{TEŞEKKÜR}

$\mathrm{Bu}$ çalışmanın arazi çalışmalarında yardımlarını esirgemeyen Orman Mühendisi Veli Altındaş, Orman Mühendisi Mustafa Coşkun'a ve Ormancılık Çalışmaları Uygulama ve Araştırma Merkezi'ne teşekkür ederiz.

\section{KAYNAKLAR}

Acar HH, Ünver-Okan S, Üçüncü K (2015) Assessment on uphill yarding with the combination of log chute and portable winch. Eur J Forest Eng 1(1): 34-40
Akay AE, Sert M, Gülci N (2014) Hafif eğimli arazilerde benzinli el vinci ile bölmeden çıkarma çalışmalarının verim açısından değerlendirilmesi. II. Ulusal Akdeniz Orman ve Çevre Sempozyumu, 22-24 Ekim 2014, Isparta, pp 281-290

Aktekin AT (2018) Odun üretim çalışmalarında verimlilik ve iş güvenliği üzerine teknik analizler. İstanbul Üniversitesi-Cerrahpaşa, Lisansüstü Eğitim Enstitüsü, Yüksek Lisans Tezi, İstanbul, $39 \mathrm{~s}$

Anonim (2012) Sarıyer Orman İşletme Şefliği Amenajman Planı

Anonim (2019) IBM SPSS istatistik programı (Kurulum CD'si)

Bilici E, Andiç VG, Akay AE, Sessions J (2019) Productivity of a portable winch system used in salvage logging of storm-damaged timber. Croation Journal of Forest Engineering 40(2): 311-318

Gülci N, Akay AE, Erdaş O (2014) Benzinli el vincinin odun hammaddesinin bölmeden çıkarılmasında kullanım imkanları. Orman Mühendisliği Dergisi Ocak/Şubat/Mart Sayısı: 24-28

Gülci N, Yüksel K, Akay AE (2017) Kar üzerinde odun hammaddesinin taşınabilir el vinci ile sürütülmesinin verim açısından değerlendirilmesi. Kastamonu Üniversitesi Orman Fakültesi Dergisi 17(1): 124-131

Gümüşay OO (2006) Ekim Makinası İmalatında Zaman Etüdü. Ankara Üniversitesi Fen Bilimleri Enstitüsü, Yüksek Lisans Tezi, Ankara, 6$12 \mathrm{~s}$

Hiesl P, Benjamin JG (2012) Cycle time analysis of harvesting equipment from an early commercial-thinning treatment in Maine. 35th Council on Forest Engineering Annual Meeting, New Bern, North Carolina, pp 1-14

LeDoux CB, Huyler NK (2000) Cost comparisons for three harvesting systems operating in nrthern hardwood stands. USDA Forest Services Research Paper NE-715, pp 1-4

Mellgren PG, Claire P (1989) More reliable multi-function woodharvesting machines in the future? Journal of Forest Engineering 1(1): 17-22

McDonald TO, Fulton JP (2005) Automated time study of skidder using global positioning system data. Computers and Electronics in Agriculture 48: 19-37

Moskalik T, Borz SA, Dvorak J, Ferencik M, Glushkov S, Muiste P, Lazdins A, Styranivsky O (2017) Timber harvesting methods in eastern european countries: A review Croat J For Eng 38(2): 231241

Russell F, Mortimer D (2005) A review of small-scale harvesting systems in use worldwide and their potential application in Irish forestry. National Council for Forest Research and Development, Ireland, pp 5-6

Sticha V, Holusa J, Sloup R, Macku J, Trombik J (2018) A mobile hydraulic winch for use in small-scale forestry. Croat J For Eng 39(2): 205-212 